\title{
MJMR LAPAROSCOPIC HERNIORRHAPHY OF SMALL SIZED MIDLINE VENTRAL HERNIAS IN DAY SURGERY UNIT RESULTS IN ACADEMIC TEACHING HOSPITAL
}

\author{
Abdel-Fatah S. Abdel-Fatah, Doaa A. Saad, Mohamad S. Farahat, Hosam M. Hamza* \\ Department of General Surgery, Minia Faculty of Medicine, Minia, Egypt \\ *Corresponding Author E-mail: hosam_hamza@ymail.com
}

\begin{abstract}
Background: Repair of ventral hernia (VH) is a commonly performed procedure. The purpose of this study is to evaluate the results of primary repair of midline $\mathrm{VH}$ using laparoscopic approach as a day surgery procedure in an academic teaching hospital. Material and methods: This prospective study was conducted in General Surgery department, Minia University Hospital, Egypt, for 82 patients with midline ventral hernias subjected to primary repair of the defect using laparoscopic approach in the period from February 2017 till February 2019. Patients were followed up for seroma, hematoma, wound infection or recurrence. Results: Study included 81 patients; 30 cases (37\%) were males and $51(63 \%)$ were females. Ages ranged from $20-57$ years. Thirty-eight (46.9\%) patients presented with epigastric hernias, $34(42 \%)$ had paraumbilical hernias, and port site hernias were found in $9(11.1 \%)$ patients. Mean width of the defect was $15 \pm 4.3 \mathrm{~mm}$. Mean operative time was $52.3 \mathrm{~min}$. All cases were done on a day surgery setting. No cases showed intestinal injury or paralytic ileus. Eighteen patients $(22.2 \%)$ developed seroma not requiring aspiration. Hematoma was seen in three $(3.7 \%)$ patients and was conservatively managed. Only two cases (2.5\%) developed superficial wound infection. Rate of recurrence was $4.9 \%$. Conclusion: Primary laparoscopic ventral hernia repair (LVHR) with defects less than $2 \mathrm{~cm}$ in diameter is a safe, simple, time-saving procedure associated with less complications, less risk of surgical site infection (SSI), shorter hospital stay and low cost.
\end{abstract}

\section{Keywords: Ventral hernia, Laparoscopic Repair, Primary Repair}

\section{INTRODUCTION}

Ventral hernia $(\mathrm{VH})$ is a non-inguinal, non-hiatal defect in the fascia of the abdominal wall. VH repair is a commonly performed procedure (Cho et al., 2019; Petro et al., 2019). One-third (by physical examination) to one-half (by radiographic imaging) of all individuals have a ventral hernia (Poulose et al., 2012).

LVHR most dramatically benefits patients with relatively small defects $(<5 \mathrm{~cm})$, who have shorter hospital stay and lower rates of SSI compared with open ventral hernia repair (OVHR) (Schlosser et al., 2019).

This study demonstrates the results of primary repair of small sized midline $\mathrm{VH}$ in an academic teaching hospital on the basis of day case surgery.

\section{PATIENTS AND METHODS}

\section{Patients: -}

A total number of 81 patients subjected to primary laparoscopic repair of midline $\mathrm{VH}$ without mesh in General Surgery department, Minia University Hospital, Egypt were enrolled in this study in the period from February 2017 till February 2019 after approval of the institutional board of ethics. Fully informed consents were taken from the patients. Inclusion and exclusion criteria are shown in table 1.

Table 1: Inclusion and exclusion criteria for participation in the study

\begin{tabular}{|c|c|}
\hline $\begin{array}{l}\text { Inclusion criteria: } \\
\text { 1. A male or female patient with } \\
\text { ONE of the following types of } \\
\text { VH: } \\
\text { i. Epigastric hernia. } \\
\text { ii. Paraumbilical } \\
\text { iii. Port site hernia. } \\
\text { 2. Patients with the age of } 20 \\
\text { years or more. } \\
\text { 3. Patients convenient for two } \\
\text { years of postoperative } \\
\text { follow-up. }\end{array}$ & $\begin{array}{l}\mathrm{r} \text { than } 20 \text { years old. } \\
\text { sting co -morbidities, drug } \\
\text { infection. } \\
\text { x "BMI" of } 35 \mathrm{~kg} / \mathrm{m}^{2} \text { or more. } \\
\text { a. } \\
\text { s. } \\
\text { a. } \\
\text { nplicated hernia. }\end{array}$ \\
\hline
\end{tabular}




\section{Methods}

Detailed clinical history was obtained, including demographic data and detailed hernia-related history. Data of clinical examination of all cases were recorded, including BMI and location of hernia defect. Measurement of the width of the hernia defect (the longest transverse distance between the fascial edges of the defect) was achieved obtained by preoperative clinical examination, preoperative Ultrasound (US) and by intraoperative measurement. Patients with VH defect $>2 \mathrm{~cm}$ were not included in our study.

Full routine laboratory investigations were done for all cases. US was done in all cases using GE LOGIQ E9 Ultrasound Machine for measurement of the width of the defect and determination of the content of the hernia sac (omentum or bowel). The previously mentioned data, operative time in minutes (from the first port site incision until the last port skin closure), postoperative pain, length of postoperative hospital stay (HOS), postoperative complications and hernia recurrence were all recorded and analyzed.

LVHR was done for all cases under general anesthesia in the supine position. Preliminary Intraoperative measurement of the width of hernia defect was done under anesthesia before establishment of $\mathrm{CO} 2$ pneumoperitoneum. The first port is inserted - by Hasson's technique or the assistance of a visiport - in the sub umbilical region for $10 \mathrm{~mm}$ angled laparoscope (30॰). Two other working ports $(5 \mathrm{~mm})$ were used for hernia defects $\leq 5 \mathrm{~mm}$ and three ports for larger defects, we generally avoid larger size of ports to reduce the risk of port site hernia. Position of these working ports depends upon the hernia location, taking in consideration to keep an adequate distance between the port site and the hernia defect.

It is our policy to accomplish preperitoneal dissection and/or adhesiolysis using sharp technique and to avoid monopolar shears in order to shun thermal bowel injury. We avoided extensive adhesiolysis and bowel manipulation to decrease the chance of postoperative ileus.

Using atraumatic graspers, contents of the hernia was assessed and reduced before the peritoneal sac is excised (figure 1 shows a view for the hernia defect and its content). The peritoneal surface of the abdominal wall is carefully inspected for other defects. An area of $3 \mathrm{~cm}$ all around from the margins of the defect are cleared of adhesions. Width of the defect is now measured again to determine the plan for closure.

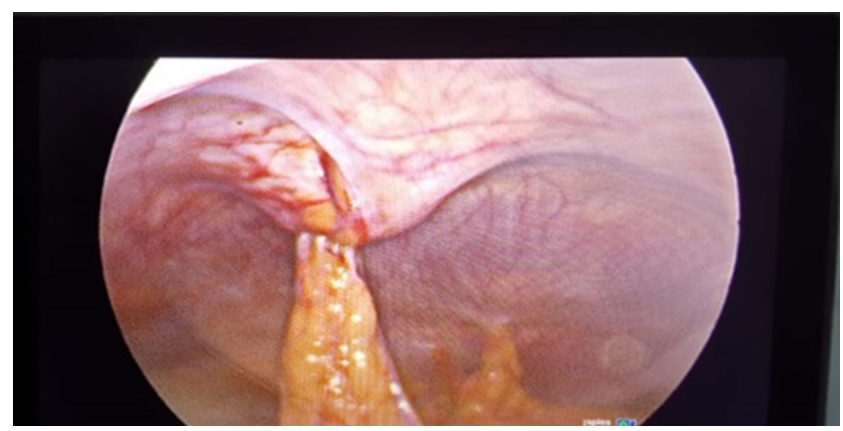

Figure 1: view for the hernia defect and its content

Facial edges of defect were closed longitudinally by the use of transversely placed interrupted sutures using a suture passer. Two stitches (one 0-polyglactin and one 0 -polyproline sutures) were taken to close small defects $\leq 5 \mathrm{~mm}$ in width, and three stitches (two 0-polyglactin and one 0-polyproline sutures) for defects larger than 5 $\mathrm{mm}$. A transcutaneous suture passing device was used to pass sutures through the anterior abdominal wall. Sutures are securely tied after partial desufflation of pneumoperitoneum. Final view of the defect after herniorrhaphy is shown in figure 2 .

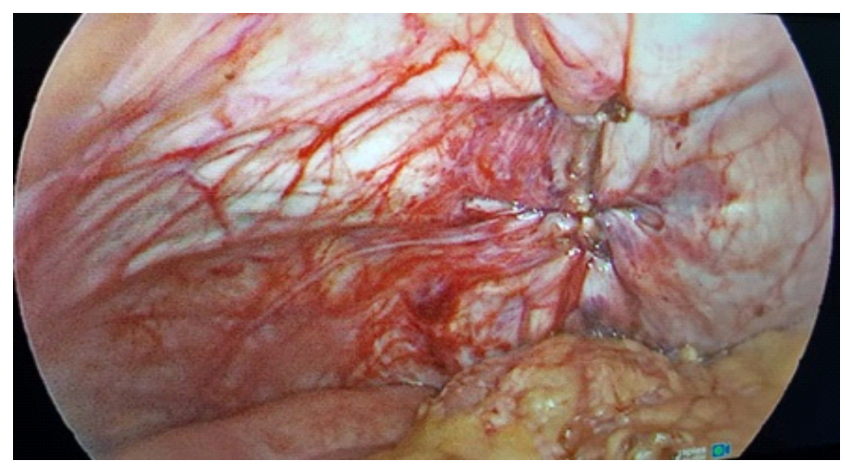

Figure (2): final view of the defect after herniorrhaphy

Adequate closure of the defect, hemostasis, exclusion of omentum/bowel entrapment in the sutures and exclusion of any organ injury were the last steps before complete desufflation of the peritoneal cavity, removal of the ports and closure of skin incisions. No drains were used. Standard postoperative care was given to all cases.

Upon discharge, patients were advised to avoid onerous work and lifting heavy objects for at least 4 weeks. 
Follow-up with respect to missed visceral injury, development of seroma, hematoma, wound infection, hernia recurrence was scheduled as follows: 3rd postoperative day, 1 st postoperative week, 2 weeks, 4 weeks, 3 months, 6 months and 24 months.

\section{Statistical analysis}

Data were analyzed using IBM SPSS software (release 25), SPSS Inc., for Windows (Microsoft), United States of America. Statistical methods included descriptive analysis, such as mean \pm standard deviation, percentage, frequencies.

\section{RESULTS}

This study included 81 patients who underwent primary laparoscopic repair of midline $\mathrm{VH}$ on a day surgery setting; 30 cases $(37 \%)$ were males and 51 $(63 \%)$ were females. Their ages ranged from $20-57$ years with mean age $37.4 \pm 9.4$ years. Thirty-eight (46.9\%) patients in our study presented with epigastric hernias, thirty-four (42\%) patients had paraumbilical hernias, and port site hernias were found in nine (11.1\%) patients after laparoscopic cholecystectomy (LC, three patients) and laparoscopic sleeve gastrectomy (LSG, six patients). Neither multiple hernias nor multiple defects were seen in our cases. The mean width of the defect was $15 \pm 4.3 \mathrm{~mm}$ (range, $5-20 \mathrm{~mm}$ ). Clinical and demographic characteristics of our patients are shown in table 2 .

Table 2: Demographic and clinical characteristics of patients enrolled in our study

\begin{tabular}{|c|c|}
\hline Characteristic & $\begin{array}{c}\text { Total } \\
(\mathbf{n}=\mathbf{8 1})\end{array}$ \\
\hline Age (year) & $20-57$ \\
Range & $37.4 \pm 9.4$ \\
Mean \pm SD & \\
\hline Sex & $30(37 \%)$ \\
Male & $51(63 \%)$ \\
Female & $38(46.9 \%)$ \\
\hline Type of hernia & $34(42 \%)$ \\
Epigastric & $9(11.1 \%)$ \\
Paraumbilical & $3(3.7 \%)$ \\
Port site & $6(7.4 \%)$ \\
post $L C$ & \\
post $L S G$ & $5-20$ \\
Range & 16 \\
Median & $15 \pm 4.3$ \\
Mean \pm SD & \\
\hline
\end{tabular}

During operation, none of our cases showed hernia defect that couldn't be detected by preoperative clinical examination (occult defect). All cases were completed by laparoscopy with $0 \%$ rate of conversion to open surgery and no cases of bleeding during adhesiolysis or bleeding from port site were encountered. The mean operative time was 52.3 min (range, $38-60 \mathrm{~min}$ ). We used the 'numerical pain rating scale' for assessment of postoperative pain, in which the patient is asked to indicate the intensity of current, best, and worst pain levels on a scale of 0 (no pain) to 10 (worst pain imaginable). Only two female cases $(2.5 \%)$ had the score of $4-6$ on the numerical score in the first 24 hours postoperatively, indicating moderate pain, the scores of the remaining seventy-nine cases $(97.5 \%)$ were in the range of $1-3$ indicating mild pain intensity. All cases were done on a day surgery setting, and all were uneventfully discharged within 12 hours after surgery. The mean HOS was 8 \pm 3.2 hours.

During the early postoperative follow-up, we found no cases with intestinal injury or paralytic ileus. Eighteen patients $(22.2 \%)$ developed seroma not requiring aspiration and not persistent for more than 45 days with clinical and radiological (US) follow up of the size of seroma. Hematoma was seen in three $(3.7 \%)$ patients and was conservatively managed. Only two cases $(2.5 \%)$ developed SSI, infection was superficial in both cases and responded rapidly to oral antibiotics and repeated wound dressing without the need for further procedures.

If clinical examination of the site of the previously operated hernia during the period of follow-up revealed a swelling with the characters of hernia, this is defined as hernia recurrence. Rate of recurrence was $4.9 \%$; late in the follow-up period, four out of the eighty-one cases developed recurrent hernia at a mean follow-up of 20 months as shown in table 3 . 
Table 3: Operative data and postoperative outcome in our study

\begin{tabular}{|l|c|}
\hline & $\begin{array}{c}\text { Total } \\
(\mathbf{n}=\mathbf{8 1})\end{array}$ \\
\hline Multiple defects & $0 \%$ \\
\hline Occult defects & $0 \%$ \\
\hline Rate of conversion to open surgery & $0 \%$ \\
\hline Operative time (min) & $38-60$ \\
Range & $52.3 \pm 5.6$ \\
Mean \pm SD & \\
\hline Postoperative pain & $79(97.5 \%)$ \\
Mild & $2(2.5 \%)$ \\
Moderate & \\
\hline HOS (hours) & 8 \\
Median & $8 \pm 3.2$ \\
Mean \pm SD & $0 \%$ \\
\hline Intraoperative complications & $0 \%$ \\
Visceral injury & \\
Bleeding from port sites & $0 \%$ \\
\hline Postoperative complications & $18(22.2 \%)$ \\
Ileus & $3(3.7 \%)$ \\
Seroma & $2(2.5 \%)$ \\
Haematoma & $4(4.9 \%)$ \\
SSI & $0 \%$ \\
Recurrence & $0 \%$ \\
Mortality & \\
Emergent hospital admission & \\
\hline
\end{tabular}

Recurrence was associated with maximum reported pain as the two cases who suffered from moderate postoperative pain developed recurrence. During the whole period of follow-up (24 months) we reported no cases of mortality or emergent hospital admission due to LVHR - related complications.

\section{DISCUSSION}

Surgical volume has shifted significantly from inpatient to outpatient settings, including free-standing ambulatory surgery centers (Davis et al, 2019). Repair of ventral hernias by laparoscopic approach has the benefit of smaller incisions, and therefore, fewer complications related to wound (Begum and Khan, 2018). Laparoscopic herniorraphy of small sized ventral hernias is preferred over the hernioplasty because the prosthetic material is unnecessary. Its advantages include short operative time with no additional cost or hospital stay with avoidance of mesh related complications such as infected mesh and seroma (Begum and Khan, 2018).

In this study, patients' age ranged from $20-57$ years with mean age of $37.4 \pm 9.4$, this is to some extent similar to the results recently published by Kappikeri and
Thalasta who found the majority of the observed hernias to be ventral hernias observed in the age group of 31-40 years (Kappikeri and Thalasta, 2017). The number of female patients in our study is higher than the number of male patients ( $63 \%$ versus $37 \%$ respectively), and that is consistent with the results of several previous studies (Begum and Khan, 2018; Ujiki et al, 2004; Ecker et al, 2016)

The findings of Juo and co-workers do not agree with ours; as they had the number of male patients (2455 patients, $68.3 \%$ ) exceeding that of female patients (1139 patients, 31.7\%) (Juo et al, 2017).

With more and more use of LVHR, many patients with $\mathrm{VH}$ were found to have occult defects detected by direct visualization at the time of laparoscopy. In one series, nearly half of the patients undergoing laparoscopic ventral hernia repair were found to have occult hernia defects not found on pre-operative physical examination (Saber et al, 2008). Sharma et al. in their series of 1,242 LVHR reported 203 occult hernias (Sharma et al, 2011) None of our cases had occult defects.

We used to measure the width of hernia defect intraoperatively and not to rely only on preoperative clinical and US assessment alone, this plan is supported by the results of Emanuelsson and his colleagues who found that clinical assessment corresponded more precisely to the intraoperative measurement of the hernia than a CT scan (Emanuelsson et al, 2014).

Lindmark et al. reported that assessment of hernia aperture size is of great importance in the preoperative evaluation of ventral hernia patients to consider risk for post-operative complications and that the clinician should be aware that the time span between clinical assessment or a CT scan and the time of surgery may allow for an increase in the hernia size (Lindmark et al, 2018).

Repair of VH was accomplished by the laparoscopy in all the studied 81 cases ( $0 \%$ conversion to open surgery). Different rates of conversion to open repair have been reported in other studies. Rogmark and co-workers had a rate of $7.8 \%$ (Rogmark et al, 2013), 11.7\% with Langbach and co-workers (Langbach et al, 2015), and $5 \%$ with Basheer and co-workers (Basheer et al, 2018)

In our study, no cases of intraoperative bleeding have been encountered. One can encounter bleeding during 
trocar insertion or while manipulating or dissecting viscera. Bleeding can also arise albeit more frequently during adhesiolysis (Salgaonkar, Wijerathne, and Lomanto, 2019)

The mean operative time was $52.3 \pm 5.6$ minutes (range, $38-60 \mathrm{~min}$ ). Anadol et al reported a mean operation time of $23.5 \mathrm{~min}$ (Anadol et al, 2010)

In the first 24 hours after operation, two female cases in our study $(2.5 \%)$ experienced moderate postoperative pain, the remaining seventy-nine cases $(97.5 \%)$ experienced mild pain intensity. In agreement with our results, Langbach and co-workers (Langbach et al, 2017) reported that female gender was associated with maximum reported pain after LVHR. Basheer et al. reported a statistical significance regarding the postoperative pain score within 24 hours postoperatively between laparoscopic repair group (a mean of $4.11 \pm 1.91$ ) versus the open repair group (a mean of 6.45 \pm 1.24 ) (Basheer et al, 2018).

Seroma is a common postoperative finding after $\mathrm{VH}$ repair with an incidence of $20 \%$. Because it is common, it is often an accepted outcome (Stoikes et al, 2018). It is commonly seen after few days, its peak presentation is about 7 days after operation. Almost all seromas will invariably resolve by 90 days post-surgery (44-48) (Salgaonkar et al, 2019).

In our study, 18 (22.2\%) patients developed seroma during early postoperative follow-up. All patients with seromas were managed by observation as no seromas were requiring aspiration neither persistent for more than 45 days.

Many surgical techniques can help to reduce the incidence of post $\mathrm{VH}$ repair seroma. In a recently published randomized controlled study over 370 patients with large ventral hernias, Alhussini and coworkers found that quilting sutures is an effective and easy technique to reduce post-ventral hernia seroma accumulation (Alhussini, Awad, and Kholosy, 2019)

Three cases $(3.7 \%)$ developed hematoma during early postoperative follow-up and all were dealt with without further intervention; two cases were managed by watchful observation and the third one benefited from warm compresses and compression with an abdominal binder.
Hematomas can occur due to trocar entry, especially the cutting trocars, and can also be seen within the hernial sac, usually due to adhesiolysis. Timely management of intraoperative hemorrhage will arrest the development of intra-muscular or extra-peritoneal hematoma (Salgaonkar et al, 2019).

LVHR is associated with a low incidence of postoperative ileus, with few patients with no return of bowel activity after five days. Patients who require extensive adhesiolysis and/or manipulation of the intestine, or heavy postoperative narcotic use are at higher risk of developing ileus (Shah and Liang, 2019). This coincided with our results as none of our cases $(0 \%)$ developed ileus after the procedure.

The common complications after OVHR are woundrelated problems including infection, hematoma, stitch sinus, and flap necrosis (Choi and Lee, 2018). Compared with open ventral hernia repair, laparoscopic repair causes fewer surgical site infections, both superficial and deep (Shah and Liang, 2019) The reduced risk is the result of smaller incisions, probability of bacteria lodging in the subcutaneous space, reduced hospital stay and operative time (Salgaonkar et al, 2019).

In our study, only two cases (2.5\%) developed SSI, infection was superficial in both cases and responded rapidly to oral antibiotics and repeated wound dressing without the need for further intervention.

Our rate of recurrence was $4.9 \%$; four out of the eightyone cases developed recurrent hernia. This result is similar to the results of previous studies by Siirtola et al. with $4.2 \%$ recurrence rate and Stickel et al. with 5.2\% recurrence rate (Ahonen-Siirtola et al, 2015; Stickel et al, 2007).

However, recurrence was absent in laparoscopic repair by Tsuruta and his colleagues (Tsuruta, Hirai, and Nakamura 2014) and by Barbaros and his colleagues (Barbaros et al, 2007). It seems that the learning curve of the laparoscopic repair plays an important role in the recurrence rate of this procedure (Basheer et al, 2018).

Recurrence in our cases was associated with maximum reported pain as the two cases who suffered from moderate postoperative pain developed recurrence, this coincided with the results of Langbach and his 
colleagues (Langbach et al, 2015)

To our knowledge, no previous studies has been published about mesh-less primary LVHR as a day case procedure. Day case surgery is associated with shortened hospital stay and earlier mobilisation and also reduces the risk of hospital-acquired infections and venous thromboembolism (Bailey et al, 2019)

\section{CONCLUSION}

Primary LVHR with defects less than $2 \mathrm{~cm}$ in width done on an ambulatory basis is a safe, simple, timesaving procedure associated with less complications, less risk of SSI, shorter hospital stay and low cost.

\section{CONFLICT OF INTERESTS}

The authors declare that they have no conflict of interest.

\section{REFERENCES}

Ahonen-Siirtola M, Rautio T, Ward J, Kossi J, Ohtonen P, Makala J. Complications in laparoscopic versus open incisional ventral hernia repair. A retrospective comparative study. World Journal of Surgery. 2015;39(12): 2872-77.

Alhussini MA, Awad AT, Kholosy HM. Using quilting sutures in decreasing seroma formation after managing large ventral hernias: a comparative study. Hernia. 2019:23(4):717-22

Anadol AZ, Tezel E, Yilmaz U, Kurukahvecioglu O, Ersoy E. Laparoscopic primary repair of ventral hernias: early results of a new technique. Surg Today. 2010;40(1):88-91.

Bailey C, Ahuja M, Bartholomew K, et al. Guidelines for day-case surgery 2019. Anaesthesia. 2019;74(6):778-92.

Barbaros U, Asoglu O, Seven R, et al. The comparison of laparoscopic and open ventral hernia repairs: a prospective randomized study. Hernia. 2007;11(1):51-56.

Basheer M, Negm A, El-Ghadban H, Samir M, Hadidy A, Dawoud I. Laparoscopic versus open ventral hernia repair: a comparative study. Egypt Journal of Surgery. 2018;37(4):465-71.

Begum S, Khan MR. Outcome assessment of primary ventral versus incisional hernia repair by laparoscopic approach. International Journal of Abdom Wall Hernia Surgery. 2018;1(3):94-98.

Cho JE, Helm MC, Helm JH, et al. Retro-rectus placement of bio-absorbable mesh improves patient outcomes. Surgery of Endo science. 2019;33(8):2629-34

Choi YB, Lee IS. Incisional and Ventral Hernia Repair. Journal Minim Invasive Surgery. 2018;21(1):5-13.

Davis K, Mahishi V, Singal R, et al. Quality Improvement in Ambulatory Surgery Centers: A Major National Effort Aimed at Reducing Infections and Other Surgical Complications. Journal Clinic Medical Research. 2019;11(1):7-14.

Ecker BL, Kuo LE, Simmons KD, Fischer JP, Morris JB, Kelz RR. Laparoscopic versus open ventral hernia repair: longitudinal outcomes and cost analysis using statewide claims data. Surgery of Endosc. 2016;30(3):906-15.

Emanuelsson P, Dahlstrand U, Strömsten U, Gunnarsson U. Strigård K, Stark B. Analysis of the abdominal musculo-aponeurotic anatomy in rectus diastasis: comparison of CT scanning and preoperative clinical assessment with direct measurement intraoperatively. Hernia. 2014;18(4):465-71.

Juo YY, Skancke M, Holzmacher J, Amdur RL, Lin PP, Vaziri K. Laparoscopic versus open ventral hernia repair in patients with chronic liver disease. Surg Endosc. 2017;31(2):769-77.

Kappikeri VS, Thalasta P. Clinical study of hernia in females. International Surgery Journal. 2017;4(5):1632-36

Langbach O, Bukholm I, Benth JS, Rokke O. Long term recurrence, pain and patient satisfaction after ventral hernia mesh repair. World Journal of Gastrointest Surgery. 2015;7(12) pp:384-93.

Lindmark M, Strigård K, Löwenmark T, Dahlstrand U, Gunnarsson U. Risk Factors for Surgical Complications in Ventral Hernia Repair. World Journal Surgery. 2018;42(11) pp:3528-36.

Petro CC, Haskins IN, Perez AJ, (2019) Hernia repair in patients with chronic liver disease - A 15-year single-center experience. American Journal Surgery. ;217(1) pp:59-65. 
Poulose BK, Shelton J, Phillips S, et al. Epidemiology and cost of ventral hernia repair: making the case for hernia research. Hernia. 2012;16(2):179-83

Rogmark P, Petersson U, Bringman S, et al. Short-term outcomes for open and laparoscopic midline incisional hernia repair: a randomized multicenter controlled trial: the ProLOVE (prospective randomized trial on open versus laparoscopic operation of ventral eventrations) trial. Ann Surg. 2013;258(1):37-45.

Saber AA, Rao AJ, Itawi EA, Elgamal MH, Martinez RL. Occult ventral hernia defects: A common finding during laparoscopic ventral hernia repair. American Journal Surgery. 2008;195(4):471-73.

Salgaonkar H, Wijerathne S, Lomanto D. (2019) Managing complications in laparoscopic ventral hernia. Annals of Laparoscopic and Endoscopic Surgery. 4:11.

Schlosser KA, Arnold MR, Otero J, (2019) Deciding on Optimal Approach for Ventral Hernia Repair: Laparoscopic or Open. Journal of the American College of Surgeons. 228(1):54-65.

Shah SK, Liang MK. Laparoscopic ventral hernia repair. ed. UpTo Date. Waltham, MA: UpToDate Inc. https://www.uptodate.com (Literature review current through: May 2019).

Sharma A, Mehrotra M, Khullar R, Soni V, Baijal M, Chowbey PK. (2011) Laparoscopic ventral/incisional hernia repair: a single centre experience of 1,242 patients over a period of 13 years. Hernia.15(2):131-39.

Stickel M, Rentsch M, Clevert DA, (2007) Laparoscopic mesh repair of incisional: an alternative to the conventional open repair. Hernia.11(3):217-22.

Stoikes N, Roan E, Webb D, (2018) The Problem of Seroma After Ventral Hernia Repair. Surgery Technology International. 32:93-98.

Tsuruta A, Hirai T, Nakamura M. (2014) Retrospective comparison of open versus laparoscopic ventral and incisional hernia repair. Asian Journal of Endosc Surgery.7(3):246-50.

Ujiki MB, Weinberger J, Varghese TK, Murayama KM, Joehl RJ. (2004) One hundred consecutive laparoscopic ventral hernia repairs. American Journal of Surgery;188(5):593-97. 